\title{
The Effects of Stair Climbing Training with Functional Electrical Stimulation on Muscle Strength, Balance, and Gait in Patients with Chronic Stroke
}

\author{
Sieun Koh ${ }^{a}$, Wonjae Choi $^{b}$, Seungwon Lee ${ }^{c, d}$

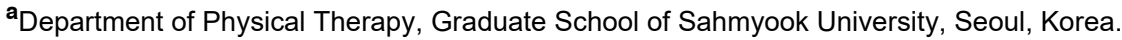 \\ b Department of Physical Therapy, Joongbu University, Geumsan-gun, Korea. \\ ${ }^{\mathrm{c}}$ Department of Physical Therapy, College of Health and welfare, Sahmyook University, Seoul, Korea. \\ dInstitue of SMART rehabilitation, Sahmyook University
}

Objective: The weakness of muscle strength due to stroke affects the posture control and gait in the patients with stroke. Stroke This study examined the effects of the stair climbing training with functional electrical stimulation on muscle strength, dynamic balance, and gait in individuals with chronic stroke.

Design: Randomized controlled trial.

Methods: Total forty-eight patients were randomly assigned to the 3 groups. Participants randomly divided to stair climbing training with functional electrical stimulation group ( $\mathrm{SCT}+\mathrm{FES}$ group, $\mathrm{n}=16$ ), stair climbing training group (SCT group, $\mathrm{n}=16$ ) and control group $(\mathrm{n}=16)$. Subjects in the SCT+FES group and SCT group performed stair walking training with and without functional electrical stimulation for 30 minutes, 3 sessions per week for 4 weeks and all subjects received conventional physical therapy for 30 minutes with 5 sessions per week for 4 weeks. Outcome measurements were assessed using the sit-to stand Test for strength, timed up and go test and modified-timed up and go test for dynamic balance, and $10 \mathrm{~m}$ walk test and GaitRite system for gait.

Results: In the SCT+FES group, subjects have been shown the significant increase in lower extremity strength ( $p<0.05$ ), significantly improve in dynamic balance $(p<0.05)$, and significantly improve in their temporal gait parameter $(p<0.05)$. The SCT+FES group was significantly better than other groups in all parameters $(\mathrm{p}<0.05)$.

Conclusions: This result suggested that the SCT+FES may be effective strategy to improve muscle strength, dynamic balance, and gait for individuals with chronic stroke.

Key Words: Electric stimulation therapy, Stroke, Muscle strength, Postural balance, Gait

\section{Introduction}

Stroke patients use frequently less affected side more than affected side in activities of daily living. Both side muscles experienced imbalanced weakness [1]. They face asymmetrical position and weight bearing when sit-to-stand, result in increasing postural sway that cause easily falls to affected side $[2,3]$. Stroke patients experience weakness in affected lower limb, such as knee and ankle extensor and hip flexor, which has been reported to have a significant correlation with their gait ability $[4,5]$. Stroke patients can enhance their gait ability by improving the muscle strength in the relatively weaker affected side. In this sense, the necessity to improve muscle strength on the affected side has been emphasized in gait training of stroke patients [6]. Various rehabilitation approaches have been made to restore gait ability of stroke patients, which include lower limb strength training [7], treadmill training [8], robot-assisted training [9]. Some intervention methods

Received: Mar 2, 2021 Revised: Mar 15, 2021 Accepted: Mar 15, 2021

Corresponding author: Seungwon Lee (ORCID https://orcid.org/0000-0002-0413-0510)

Department of Physical Therapy, Sahmyook University, 815 Hwarang-ro, Nowon-gu, Seoul, 01795, Korea

Tel: +82-2-3399-1630 Fax:+82-2-3399-1639(fax) E-mail: swlee@syu.ac.kr

This is an Open-Access article distributed under the terms of the Creative Commons Attribution Non-Commercial License (http://creativecommons.org/licenses/ by-nc/4.0) which permits unrestricted non-commercial use, distribution, and reproduction in any medium, provided the original work is properly cited.

Copyright (c) 2021 Korean Academy of Physical Therapy Rehabilitation Science 
have been researched and proven their effectiveness. Of them, overground gait training has been widely used as a therapeutic approach for stroke patients. In particular, stair climbing can be a good alternative to develop lower extremity muscle strength because it causes repetitive concentric and eccentric contraction of lower extremity [10].

Stroke patients who returned to the community need to walk in a various environments because they are exposed to specific environments such as stairs climbing or obstacles in everyday life [11]. In a previous study, stroke patients were examined to their electromyogram (EMG) while climbing on stairs. As a result, muscle activity of tibialis anterior (TA) was showed to be higher during the stance phase of the affected side and the less affected side [12]. An appearance of increasing weight shifting into affected side leads to an increase of muscle activity of TA and the experience like this makes stroke patients develop postural control.

In other studies, by applying functional electrical stimulation (FES) on dorsiflexion muscle, positive effects have been observed such as gait speed increase, range of motion of ankle joint increase, stiffness reduction of gastrocnemius, and tibialis anterior muscle strength increase [13]. Various studies on FES have been conducted to improve gait ability of stroke patients, but most of the previous studies focus on kinematic analysis, joint moment, and muscle activity for older adults and patients with orthopedic diseases [14-16]. Research on the effects of motor function in stroke patients is still lack.

Stair climbing and FES was widely applied along with conservative physical therapy to improve the walking ability of patients with stroke. However, until now, studies that have applied the two interventions separately are dominant [17-19], and there are no studies that have applied FES to functional movements such as stair climbing. Therefore, the aim of this study was to investigate effects of the stair climbing training with functional electrical stimulation (SCT+FES) on muscle strength, dynamic balance, and gait in patients with chronic stroke.

\section{Methods}

\section{Participants and procedure}

This study was designed as a randomized control trial, and forty-eight participants with chronic stroke were recruited for this study. Inclusion criteria were (1) hemiparesis patients diagnosed with attack $>6$ months (2) able to walk independently for at least $10 \mathrm{~m} \mathrm{(3)}$ Functional Ambulation Category (FAC) $\geq 3$ scores [20] (4) no other an allergic response to FES (5) no other chronic pain in low limb and contracture in hip, knee, and ankle joint. Exclusion criteria were (1) diagnosed cerebellum disease (2) individuals with visual impairment, aphasia, hearing impairment (3) having other neurological or orthopedic diseases possibly affecting this research. All participants were evaluated and screened by the inclusion and exclusion criteria. Informed consent was voluntarily obtained from all patients before participation in the study, and this study was approved by the Institutional Review Board of Sahmyook University (SYUIRB2014-044).

Forty-eight subjects recruited were divided randomly into three groups, including stair climbing training with FES (SCT+FES group, $\mathrm{n}=16$ ), stair climbing training group (SCT group, $n=16)$, and control group $(n=16)$. The subjects were assessed to lower limb muscle strength, postural balance, and gait before and after training by a skilled physical therapist who understood the experiment, was good at handing the assessment tools and did not participate in the training. For the random assignment, the random sampling of SPSS program (19.0 version; IBM co., USA) was utilized. The three groups performed a conservative physical therapy for 30 minutes, twice a day, 5 times a week for 4 weeks. Subjects in the SCT+FES and SCT groups additionally performed the 30-minute training program, 3 times a week for 4 weeks. Subjects in the SCT+FES group were performed with FES, but subjects in the SCT group were performed without FES. During the training period, total 6 subjects dropped out as 4 subjects in the SCT group were discharged from the hospital and don't participant in the training program, and 2 subjects in the control group were discharged from the hospital.

\section{Intervention}

\section{Stair climbing training with functional electrical stimulation (SCT+FES)}

The FES was attached to the TA proximal part $(5 \mathrm{~cm}$ under fibula head) and distal part (5 $\mathrm{cm}$ above fibula lateral malleolus) of participants due to facilitation of 
the ankle dorsiflexion muscle. The FES waves are keeping sufficient intensity to generate good dorsiflexion and eversion so long as the patients do not complain. During gait, foot switch sensors were used to trigger stimulation for dorsiflexion in ankle joint immediately following lifting toes after heel off. By attaching the foot switch on the heel of the affected side, stimulation was let into TA during the swing phase.

\section{Stair climbing training (SCT)}

The SCT was conducted on a stair with $0.8 \mathrm{~m}$ width, $28 \mathrm{~cm}$ tread, $10 \mathrm{~cm}$ height, and $33^{\circ}$ or larger inclination. Subjects were instructed to hold the handrail, however overall do not depend on rail. The assistant therapist supervised the subjects while performing the training.

\section{Conservative physical therapy}

The subjects in the control group were only performed overground walking and conservative physical therapy. The BOBATH based on the motor development theory was used for normal treatment, and the Proprioceptive Neuromusclar Facilitation based on the motor learning theory was applied according to condition of subjects.

Outcome measurements This study used a surface Functional Electrical Stimulation (EMGFES 3000; cyber medic Inc, Korea) and foot switches (Ohmann; cyber msdic Inc, Korea) to stair walking with FES. The FES used a asymmetric biphasic waves with $30 \mathrm{~Hz}$, frequency and $300 \mu$ s pulse duration on tibialis anterior.

The sit to stand (STS) test is used to assess the lower limb muscle strength. All subjects were seated on an armless, backless chair, which was adjusted to allow for approximate 90-degree at the hip and knee joints. The distance between their feet was not constrained and the STS test was performed with shoes on. The subjects performed three self-paced STS trials without the use of their arms (arms remained relaxed by their sides) for 30 seconds. Before each trial, an assessor gave the instruction "Whenever you are ready, stand-up at a comfortable pace". The average number was recorded [21].

The timed up and go (TUG) test is used to assess dynamic balance ability. Subjects were seated in a chair with armrests and then instructed to stand (using the armrests, if desired) and walk as quickly and safely as possible for a distance of $3 \mathrm{~m}$. The subjects then turned around, returned to the chair, and sat down. The time from the point at which their spine left the back of the chair until they returned to that same position was recorded using a stopwatch [22]. The Modified Timed up and go test (Modified-TUG) is used to assess stair walking performance ability additionally. Subjects were seated in a chair with armrests and then instructed to stand and walk as quickly and safely as possible for a distance of $3 \mathrm{~m}$ including stair. In this study, ModifiedTUG has been shown to have intra-rater reliability and inter-rater reliability were respectively $\mathrm{r}=0.989$ and $\mathrm{r}=0.974$. According to Flansbjer et al. [23], a correlation between TUG and stair climbing and a correlation between TUG and stairs descending targeting chronic stroke patients were found to be high, $r=.86$ and $r=.90$, respectively.

The $10 \mathrm{~m}$ walk test (10MWT) measures gait speed, which is important for safe community mobility, such as crossing streets according to signals. The 10MWT speed in meters/second is determined by the time required to walk $10 \mathrm{~m}$. The $10 \mathrm{MWT}$ is a short, reliable, and convenient test that can be applied to any individual who is able to ambulate that distance [24]. The 10MWT tests were performed with the participants using their usual assistive devices, such as cane. Gait analysis was used electrical carpet (GaitRite; CIR system Inc., USA) for evaluating the temporospatial parameters, including gait speed, cadence. However, only temporal parameters were measured in this study. GaitRite system is a validated gait analysis system and an electronic gait analyzing board consisting of a 192 inch $(488 \mathrm{~cm})$ electrical walkway that contains six sensor pads encapsulated in a roll-up carpet to produce an active area, 24 inch $(61 \mathrm{~cm})$ wide and $0.6 \mathrm{~cm}$ high. The device measured the loading of the subject's feet with a sample rate of $80 \mathrm{~Hz}$ when the subject walks on it. The data was transmitted to the computer through a serial interface cable [25]. The temporospatial data collected was processed using GAITRite GOLD, version 3.2b Software. For this study, the subjects were instructed to walk at a comfortable speed, without the use of an assistive device.

\section{Data analysis}

For this research data analysis, SPSS ver. 19.0 was used to calculate average and standard deviation. The normality test was verified using the Shapiro-wilk test. The paired t-test was performed to pre- and post-test comparison intra-group. One-way ANOVA was used to 
determine whether there are any significant differences between the three groups. The post hoc analysis was done by the Scheffe test. To determine the statistical significance of the data collected from the subjects, the significance level was set at $\mathrm{p}<0.05$.

\section{Result}

Six of 48 were dropped, and 42 completed the training program and analyzed (Figure 1). The general characteristics of the subjects were presented in the table 1 , and there were no significant difference among the groups.

The SCT+FES group was overall significantly improved on muscle strength, dynamic balance, and gait than other two groups $(\mathrm{p}<0.05)$. In the STS, the SCT+ FES group was found to have a significant difference $(p<0.05)$, however the SCT group and control group showed no significant difference. The SCT+FES group, compared to the other two groups, was found to have a more significant increase in the lower limb muscle strength $(\mathrm{p}<0.05)$ (Table 2).

The dynamic balance was significant improved in the SCT+FES group on The TUG and modified-TUG test $(\mathrm{p}<0.05)$, however the SCT group and control group showed no significant difference. The SCT+FES group was found to have a significant improve than other two groups in the dynamic balance $(\mathrm{p}<0.05)$ (Table 2$)$.

The 10MWT and gait speed and cadence using GaitRite were found to have a significant improvement in the SCT+FES and SCT group $(\mathrm{p}<0.05)$. The 10MWT and the gait speed were significant improved in the two groups compared with the control group. However, there were no significant differences between the two groups. In the SCT+FES group, the cadence was only significant

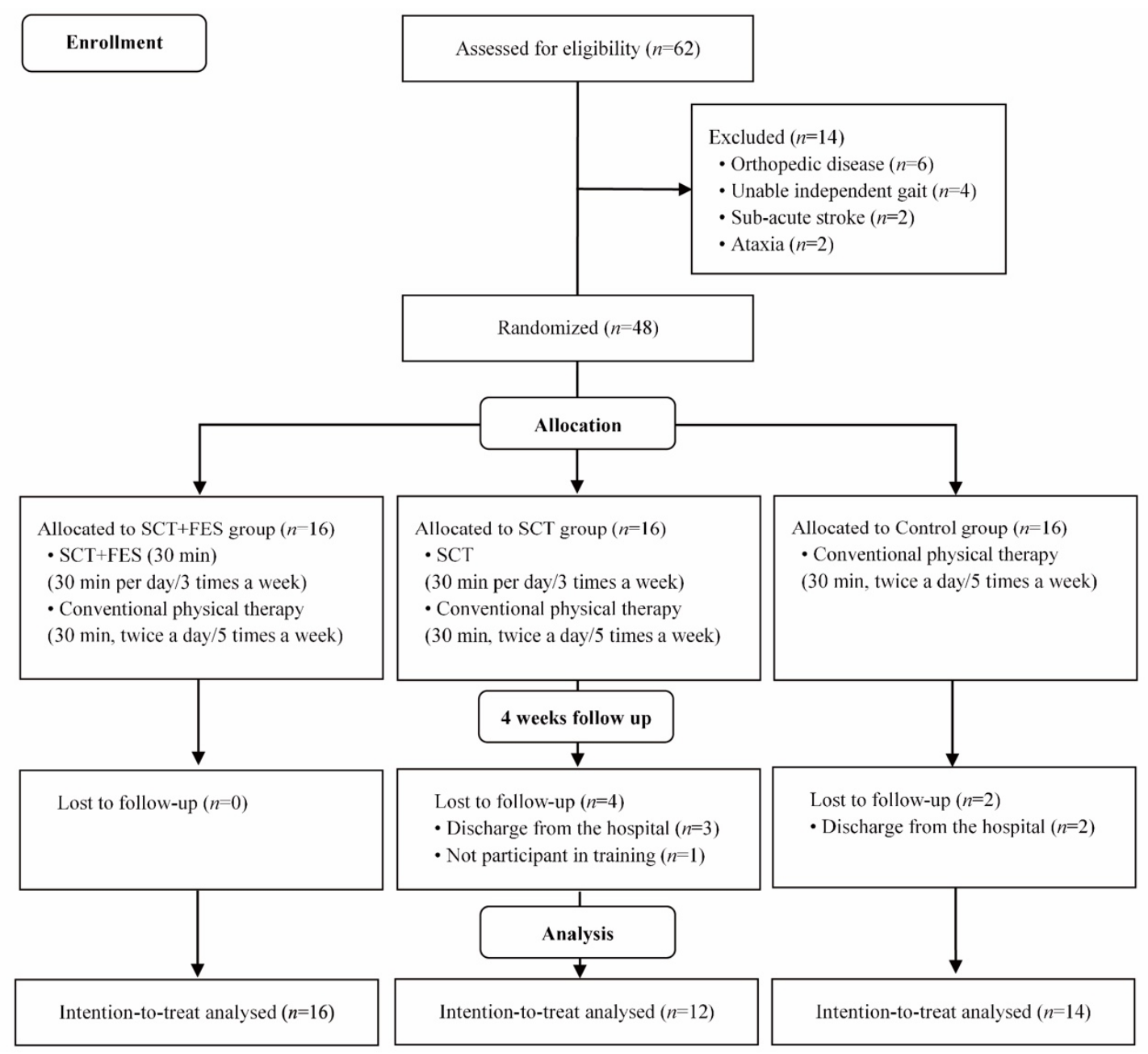

Figure 1. Flow chart of total experiment procedure 
Table1. The general characteristics of the subjects

\begin{tabular}{lllll}
\hline Variables & $\begin{array}{l}\text { SCT+FES group } \\
(\mathbf{n}=\mathbf{1 6})\end{array}$ & $\begin{array}{l}\text { SCT group } \\
(\mathbf{n}=\mathbf{1 2})\end{array}$ & $\begin{array}{l}\text { Control group } \\
(\mathbf{n}=\mathbf{1 4})\end{array}$ & $\mathbf{x}^{\mathbf{2} / \mathbf{F}(\mathbf{p})}$ \\
\hline Sex (male / female) & $12 / 4$ & $8 / 4$ & $12 / 2$ & $1.313(0.519)$ \\
Affected side (right / left) & $6 / 10$ & $4 / 8$ & $10 / 4$ & $4.820(0.090)$ \\
Duration (month) & $14.81(5.67)$ & $16.92(5.67)$ & $17.71(7.43)$ & $0.801(0.435)$ \\
Age (year) & $51.25(0.86)$ & $50.50(9.08)$ & $54.14(11.02)$ & $0.337(0.716)$ \\
Height (cm) & $166.13(3.44)$ & $165.50(6.82)$ & $167.14(3.44)$ & $0.276(0.760)$ \\
Weight (kg) & $64.07(6.40)$ & $60.00(11.04)$ & $63.71(6.36)$ & $0.901(0.414)$ \\
\hline
\end{tabular}

SCT+FES: stair climbing training with functional electrical stimulation, SCT: stair climbing training.

Value are presented as mean (SD).

Table2. Comparison of muscle strength, dynamic balance, and gait ability among the groups

$(\mathrm{n}=42)$

\begin{tabular}{|c|c|c|c|c|c|c|c|}
\hline \multirow[t]{2}{*}{ Variables } & \multicolumn{2}{|c|}{$\begin{array}{l}\text { SCT+FES group } \\
(n=16)\end{array}$} & \multicolumn{2}{|c|}{$\begin{array}{l}\text { SCT group } \\
(n=12)\end{array}$} & \multicolumn{2}{|c|}{$\begin{array}{l}\text { Control group } \\
(n=14)\end{array}$} & \multirow[t]{2}{*}{$\mathbf{F}(\mathbf{p})$} \\
\hline & Pre-test & Post-test & Pre-test & Post-test & Pre-test & Post-test & \\
\hline \multicolumn{8}{|l|}{ Muscle strength } \\
\hline $\begin{array}{l}\text { STS test } \\
\text { (numbers) }\end{array}$ & $\begin{array}{l}10.67 \\
(2.06)\end{array}$ & $\begin{array}{l}16.08 \\
(3.92)^{*}\end{array}$ & $\begin{array}{l}11.47 \\
(3.40)\end{array}$ & $\begin{array}{l}13.22 \\
(5.12)\end{array}$ & $\begin{array}{l}10.23 \\
(4.64)\end{array}$ & $\begin{array}{l}11.14 \\
(3.66)\end{array}$ & $\begin{array}{l}8.679 \\
(0.001)\end{array}$ \\
\hline \multicolumn{8}{|l|}{ Dynamic balance } \\
\hline $\begin{array}{l}\text { TUG test } \\
\text { (s) }\end{array}$ & $\begin{array}{l}20.13 \\
(5.08)\end{array}$ & $\begin{array}{l}15.40 \\
(3.71)^{*}\end{array}$ & $\begin{array}{l}19.17 \\
(9.81)\end{array}$ & $\begin{array}{l}17.96 \\
(8.85)\end{array}$ & $\begin{array}{l}20.90 \\
(9.39)\end{array}$ & $\begin{array}{l}19.85 \\
(6.76)\end{array}$ & $\begin{array}{l}8.245 \\
(0.001)\end{array}$ \\
\hline $\begin{array}{l}\text { Modified-TUG test } \\
\text { (s) }\end{array}$ & $\begin{array}{l}30.63 \\
(10.37)\end{array}$ & $\begin{array}{l}22.41 \\
(8.23)^{*}\end{array}$ & $\begin{array}{l}29.62 \\
(14.32)\end{array}$ & $\begin{array}{l}27.27 \\
(14.20)\end{array}$ & $\begin{array}{l}31.71 \\
(13.17)\end{array}$ & $\begin{array}{l}33.93 \\
(13.70)\end{array}$ & $\begin{array}{l}13.402 \\
(<0.001)\end{array}$ \\
\hline \multicolumn{8}{|l|}{ Gait ability } \\
\hline $\begin{array}{l}\text { 10MWT } \\
\text { (s) }\end{array}$ & $\begin{array}{l}17.55 \\
(4.18)\end{array}$ & $\begin{array}{l}14.69 \\
(4.32)^{*}\end{array}$ & $\begin{array}{l}19.34 \\
(9.32)\end{array}$ & $\begin{array}{l}17.20 \\
(8.70)^{*}\end{array}$ & $\begin{array}{l}19.26 \\
(12.44)\end{array}$ & $\begin{array}{l}20.84 \\
(12.29)^{*}\end{array}$ & $\begin{array}{l}24.339 \\
(<0.001)\end{array}$ \\
\hline $\begin{array}{l}\text { Gait speed } \\
(\mathrm{cm} / \mathrm{s})\end{array}$ & $\begin{array}{l}49.91 \\
(15.59)\end{array}$ & $\begin{array}{l}59.76 \\
(17.29)^{*}\end{array}$ & $\begin{array}{l}51.02 \\
(21.42)\end{array}$ & $\begin{array}{l}55.60 \\
(18.52)^{*}\end{array}$ & $\begin{array}{l}50.767 \\
(4.68)\end{array}$ & $\begin{array}{l}46.39 \\
(12.48)\end{array}$ & $\begin{array}{l}8.206 \\
(0.001)\end{array}$ \\
\hline $\begin{array}{l}\text { Cadence } \\
\text { (steps/min) }\end{array}$ & $\begin{array}{l}85.09 \\
(12.88)\end{array}$ & $\begin{array}{l}92.36 \\
(16.39)^{*}\end{array}$ & $\begin{array}{l}79.02 \\
(15.87)\end{array}$ & $\begin{array}{l}81.64 \\
(16.40)^{*}\end{array}$ & $\begin{array}{l}85.18 \\
(17.68)\end{array}$ & $\begin{array}{l}83.16 \\
(16.85)\end{array}$ & $\begin{array}{l}10.446 \\
(<0.001)\end{array}$ \\
\hline
\end{tabular}

SCT+FES: stair climbing training with functional electrical stimulation, SCT: stair climbing training, STS: sit-to-stand, TUG: timed up and go, 10MWT: 10 meter walk test.

Value are presented as mean (SD).

improved compared with control group $(\mathrm{p}<0.05)$ (Table 2)

\section{Discussion}

This study was demonstrated that the SCT+FES improves on lower limb muscle strength, dynamic postural balance, and gait in patients with chronic stroke. The imbalance of muscle strength causes asymmetrical standing balance, result in work limitation factor for walking [26]. Therefore, the recovery of walking ability in patients with stroke becomes an important goal in rehabilitation [27].

In this study, the lower limb muscle strength has found that the SCT+FES group had a most significant improvement $(\mathrm{p}<0.05)$. This is supported by the similar result of $\mathrm{Ng}$ et al. [20] reported that gait training combined with FES improved the ability to control the lower limb on the paralyzed side. However, it is almost impossible to promote muscle strength on overground. It is thus considered to be helpful to promote muscle strength in specific training, such as stairs climbing 
because they can use their body weight as a load.

SCT + FES could improve the use of affected side of subjects because training was conducted in a more advanced condition than overground walking. After all, repeated training has an important role in restoring the functions of affected side [28]. In addition, during the stair climbing, upon toe off, the FES prevent footdrop of ankle to make facilitating lower limb moment during the swing phase. As a result of dorsiflexor voluntary muscle control, the improvement is considered to have influenced an increase in muscle strength. As a result of dorsiflexor voluntary muscle control. The SCT group showed muscle strength increase but with no significant difference. It seems that the repeated training of stair ascent and descent induced the affected lower limb to have a positive effect on muscle strength increase. However, foot drop may have caused asymmetric stair climbing patterns, leading to more use of the less affected side.

This study has found a more significantly improve on dynamic balance in the SCT+FES group than the SCT group and control group $(\mathrm{p}<0.05)$. Patients with stroke had muscle weakness and impairment of proprioceptive sensation in affected side, which is accelerated by an asymmetrical posture. Patients with stroke were less likely to experience weight support to the affected side [29]. SCT+FES can be seen to improve on the dynamic balance by stimulating a proprioceptive sensation through the repeated contraction of the affected side muscle. You et al. [30] reported that limit of stability improved in patients with chronic stroke patients after applying the game of ascending and descending stairs. FES helps to restore the functional movement by reducing spasticity that interferes with normal movement in the affected side after damage of upper motor neuron, such as stroke [31]. In addition, FES stimulation of dorsiflexor helps to restore the postural balance of patients with stroke by improving the stability of the ankle [32]. Therefore, it can be interpreted that the SCT+FES training had a positive impact on improving the dynamic balance in patients with stroke. In this study, the SCT+FES group showed modified-TUG a more significant difference compared with the SCT group and control group $(\mathrm{p}<0.05)$. The improvement of the steps performance ability agreed with the results that showed the high correlation between ascending and descending stairs and the TUG test performance in a study that dealt with the reliability in 6 kinds of gait performance tests of chronic stroke patient [23].

According to Robbins et al. [33], FES improves the improvement in gait speed, stride length, and endurance. For such improvement of the gait function, the application of FES seems to have increased the efficiency of gait by helping dorsiflexion of the ankle during swing phase while gait and improving the symmetry of gait. Gait speed and cadence were showed a significant improvement in the SCT+FES group and SCT group $(p<0.05)$. These results are similar to the previous study that gait with FES stimulate ankle dorsiflexor muscles during the swing phase [34]. Therefore, FES might improve the gait ability through correcting foot drop during the swing phase in patients with stroke.

The limitation of this study was that the first is difficult to generalize because the sample size was small, second is a difference in the amount of performance to go up and down stairs at the same time according to the patient's individual ability. So, it was difficult to constantly control the amount of exercise. Finally, the spatial variable of gait could not be identified. In order to explain the qualitative improvement of gait, research on spatial variables is considered necessary in the future.

Based on the study findings, the SCT+FES is seemed an effective intervention method to improve functional activity by improving lower limb muscle strength, dynamic balance, and gait ability of patients with chronic stroke. These study implications are expected to actively contribute to improving stroke patients' physical performance in the clinical field.

\section{Acknowledgements}

This paper was supported by the Sahmyook University.

\section{Conflict of interest}

The authors declared no potential conflicts of interest with respect to the research, authorship, and/or publication of this article.

\section{References}

1. Campbell FM, Ashburn AM, Pickering RM, Burnett M. Head and pelvic movements during a dynamic 
reaching task in sitting: implications for physical therapists. Arch Phys Med Rehabil. 2001;82:1655-60.

2. Eng JJ, Chu KS. Reliability and comparison of weight-bearing ability during standing tasks for individuals with chronic stroke. Arch Phys Med Rehabil. 2002;83:1138-44.

3. Ikai T, Kamikubo T, Takehara I, Nishi M, Miyano S. Dynamic postural control in patients with hemiparesis. Am J Phys Med Rehabil. 2003;82:463-9; quiz 70-2, 84.

4. Kim CM, Eng JJ. The relationship of lower-extremity muscle torque to locomotor performance in people with stroke. Phys Ther. 2003;83:49-57.

5. Saunders DH, Greig CA, Young A, Mead GE. Association of activity limitations and lower-limb explosive extensor power in ambulatory people with stroke. Arch Phys Med Rehabil. 2008;89:677-83.

6. Aruin AS, Hanke T, Chaudhuri G, Harvey R, Rao N. Compelled weightbearing in persons with hemiparesis following stroke: the effect of a lift insert and goal-directed balance exercise. J Rehabil Res Dev. 2000;37:65-72.

7. Lamberti N, Straudi S, Malagoni AM, Argirò M, Felisatti M, Nardini E, et al. Effects of low-intensity endurance and resistance training on mobility in chronic stroke survivors: a pilot randomized controlled study. Eur J Phys Rehabil Med. 2017;53:228-39.

8. Srivastava A, Taly AB, Gupta A, Kumar S, Murali T. Bodyweight-supported treadmill training for retraining gait among chronic stroke survivors: A randomized controlled study. Ann Phys Rehabil Med. 2016;59:235-41.

9. Mustafaoglu R, Erhan B, Yeldan I, Gunduz B, Tarakci E. Does robot-assisted gait training improve mobility, activities of daily living and quality of life in stroke? A single-blinded, randomized controlled trial. Acta Neurol Belg. 2020;120:335-44.

10. Blazevich AJ, Cannavan D, Coleman DR, Horne S. Influence of concentric and eccentric resistance training on architectural adaptation in human quadriceps muscles. J Appl Physiol (1985). 2007;103: 1565-75.

11. Alzahrani MA, Dean CM, Ada L. Ability to nego- tiate stairs predicts free-living physical activity in community-dwelling people with stroke: an observational study. Aust J Physiother. 2009;55:277-81.

12. Kim YS. Muscle Activation Patterns of Stair Gait in Hemiparetic Patients Using Surface Electromyography. Journal of adapted physical activity and exercise. 2006;14:1-15.

13. Sabut SK, Sikdar C, Kumar R, Mahadevappa M. Functional electrical stimulation of dorsiflexor muscle: effects on dorsiflexor strength, plantarflexor spasticity, and motor recovery in stroke patients. NeuroRehabilitation. 2011;29:393-400.

14. Riener R, Rabuffetti M, Frigo C. Stair ascent and descent at different inclinations. Gait posture. 2002;15: $32-44$

15. Protopapadaki A, Drechsler WI, Cramp MC, Coutts FJ, Scott OM. Hip, knee, ankle kinematics and kinetics during stair ascent and descent in healthy young individuals. Clin Biomech (Bristol, Avon). 2007;22:203-10.

16. Samuel D, Rowe P, Hood V, Nicol A. The biomechanical functional demand placed on knee and hip muscles of older adults during stair ascent and descent. Gait posture. 2011;34:239-44.

17. Mitsutake T, Sakamoto M, Horikawa E. The effects of electromyography-triggered neuromuscular electrical stimulation plus tilt sensor functional electrical stimulation training on gait performance in patients with subacute stroke: a randomized controlled pilot trial. Int J Rehabil Res. 2019;42:358-64.

18. Lee D, Lee G. Effect of afferent electrical stimulation with mirror therapy on motor function, balance, and gait in chronic stroke survivors: a randomized controlled trial. Eur J Phys Rehabil Med. 2019;55:442-9.

19. Hesse S, Tomelleri C, Bardeleben A, Werner C, Waldner A. Robot-assisted practice of gait and stair climbing in nonambulatory stroke patients. Rehabil Res Dev. 2012;49:613-22.

20. Ng MF, Tong RK, Li LS. A pilot study of randomized clinical controlled trial of gait training in subacute stroke patients with partial body-weight support electromechanical gait trainer and functional 
electrical stimulation: six-month follow-up. Stroke. 2008;39:154-60.

21. Jones CJ, Rikli RE, Beam WC. A 30-s chair-stand test as a measure of lower body strength in community-residing older adults. Res Q Exerc Sport. 1999; 70:113-9.

22. Podsiadlo D, Richardson S. The timed "Up \& Go": a test of basic functional mobility for frail elderly persons. J Am Geriatr Soc. 1991;39:142-8.

23. Flansbjer UB, Holmback AM, Downham D, Patten C, Lexell J. Reliability of gait performance tests in men and women with hemiparesis after stroke. J Rehabil Med. 2005;37:75-82.

24. Broderick P, Horgan F, Blake C, Ehrensberger M, Simpson D, Monaghan K. Mirror therapy and treadmill training for patients with chronic stroke: a pilot randomized controlled trial. Top Stroke Rehabil. 2019;26:163-72.

25. Yang YR, Wang RY, Chen YC, Kao MJ. Dual-task exercise improves walking ability in chronic stroke: a randomized controlled trial. Arch Phys Med Rehabil. 2007;88:1236-40.

26. Engardt M, Knutsson E, Jonsson M, Sternhag M. Dynamic muscle strength training in stroke patients: effects on knee extension torque, electromyographic activity, and motor function. Arch Phys Med Rehabil. 1995;76:419-25.

27. Scianni A, Teixeira-Salmela LF, Ada L. Effect of strengthening exercise in addition to task-specific gait training after stroke: a randomised trial. Int $\mathrm{J}$ Stroke. 2010;5:329-35.

28. Farhat F, Hsairi I, Baati H, Smits-Engelsman BC, Masmoudi K, McHirgui R, et al. The effect of a motor skills training program in the improvement of practiced and non-practiced tasks performance in children with developmental coordination disorder (DCD). Hum Mov Sci. 2016;46:10-22.

29. Danielsson A, Willén C, Sunnerhagen KS. Measurement of energy cost by the physiological cost index in walking after stroke. Arch Phys Med Rehabil. 2007;88: 1298-303.

30. You SH, Jang SH, Kim YH, Hallett M, Ahn SH, Kwon YH, et al. Virtual reality-induced cortical re- organization and associated locomotor recovery in chronic stroke: an experimenter-blind randomized study. Stroke. 2005;36:1166-71.

31. Rushton D. Functional electrical stimulation and rehabilitation-an hypothesis. Med Eng Phys. 2003; 25:75-8.

32. Lyons GM, Sinkjaer T, Burridge JH, Wilcox DJ. A review of portable FES-based neural orthoses for the correction of drop foot. IEEE Trans Neural Syst Rehabil Eng. 2002;10:260-79.

33. Robbins SM, Houghton PE, Woodbury MG, Brown JL. The therapeutic effect of functional and transcutaneous electric stimulation on improving gait speed in stroke patients: a meta-analysis Arch Phys Med Rehabil. 2006;87:853-9.

34. Kesar TM, Perumal R, Reisman DS, Jancosko A, Rudolph KS, Higginson JS, et al. Functional electrical stimulation of ankle plantarflexor and dorsiflexor muscles: effects on poststroke gait. Stroke. 2009;40:3821-7. 